\title{
Enhanced Photovoltaic Performance of Indacenodithiophene-Quinoxaline Copolymers by Side- Chain Modulation
}

\author{
Dongfeng Dang, Weichao Chen, Scott Himmelberger, Qiang Tao, Angelica Lundin, \\ Renqiang Yang,* Weiguo Zhu,* Alberto Salleo, Christian Müller, and Ergang Wang*
}

Polymer solar cells (PSCs) have been intensively investigated in recent years due to several advantages such as low cost, light weight, and flexibility. ${ }^{[1]}$ Bulk-heterojunction (BHJ) blends of conjugated donor polymers and fullerene acceptors ${ }^{[2]}$ now offer power conversion efficiencies (PCEs) of up to $8-9 \% .{ }^{[3]}$ Current synthesis efforts focus on high-performance donor polymers that feature broad absorption spectra, high chargecarrier mobilities and suitable energy levels. ${ }^{[1,4]}$ Donor-acceptor (D-A) polymers, which combine an electron-rich and electrondeficient unit, respectively, are particularly promising, ${ }^{[1,5]}$ since judicious selection of the D and A units permits fine-tuning of the energy levels and charge transport properties. Then, optimization of a given D-A combination with respect to solubility, crystallinity and molecular weight can be achieved by selecting suitable side chains. ${ }^{[6]}$

One promising electron-rich donor unit is indacenodithiophene (IDT), which due to its high degree of planarity offers enhanced electron delocalization and thus a high charge-carrier mobility. ${ }^{[7]}$ Among reported IDT-based donor materials, the highest PCE of $7.5 \%$ has been obtained with an IDT-thiophene-quinoxaline-thiophene copolymer that carries para-hexylphenyl side chains on the IDT unit. ${ }^{[8]}$ Recently, we studied a series of thiophene-quinoxaline copolymers and found that

D. Dang, Q. Tao, Dr. A. Lundin, Dr. C. Müller,

Dr. E. Wang

Department of Chemical and

Biological Engineering/Polymer Technology

Chalmers, University of Technology

SE-412 96, Göteborg, Sweden

E-mail: ergang@chalmers.se

D. Dang, Q. Tao, Prof. W. Zhu

Key Lab of Environment-Friendly Chemistry and Application of the

Ministry of Education

College of Chemistry, Xiangtan University

Xiangtan 411105 , China

E-mail: zhuwg18@126.com

Dr. W. Chen, Prof. R. Yang

Qingdao Institute of Bioenergy and Bioprocess Technology

Chinese Academy of Sciences

189 Songling Rd., Qingdao 266101, China

E-mail: yangra@qibebt.ac.cn

S. Himmelberger, Prof. A. Salleo

Department of Material Science and Engineering

Stanford University

476 Lomita Mall, Stanford, CA 94305, USA

DOI: 10.1002/aenm.201400680 the use of meta-alkyl-phenyl instead of para-alkyl-phenyl side chains considerably enhances the solubility, molecular weight and photovoltaic performance..$^{[9]}$ Thus, here we explore to what extent this strategy, which so far has only been used for few donor materials, benefits the photovoltaic performance of IDTbased copolymers.

To this end, we designed and synthesized four copolymers with an IDT donor unit, which carried either para-hexyl-phenyl or meta-hexyl-phenyl side chains, and a thiophene-quinoxalinethiophene acceptor unit (Figure 1). We chose to work with two types of acceptors: a non-fluorinated unit (TQ) as well as a fluorinated unit (TQF), which can be expected to feature a slightly lower highest occupied molecular orbital (HOMO) level due to the electron-withdrawing effect of the fluorine atom. ${ }^{[10]}$ All polymers were prepared via the Stille coupling reaction between bis(trimethyltin) IDT monomers and bromides of thiophene-flanked quinoxaline (see Supporting Information for more details on synthesis). Different reaction times were used for each polymer to control the molecular weight and ensure good solubility. The batches used in this study were those with
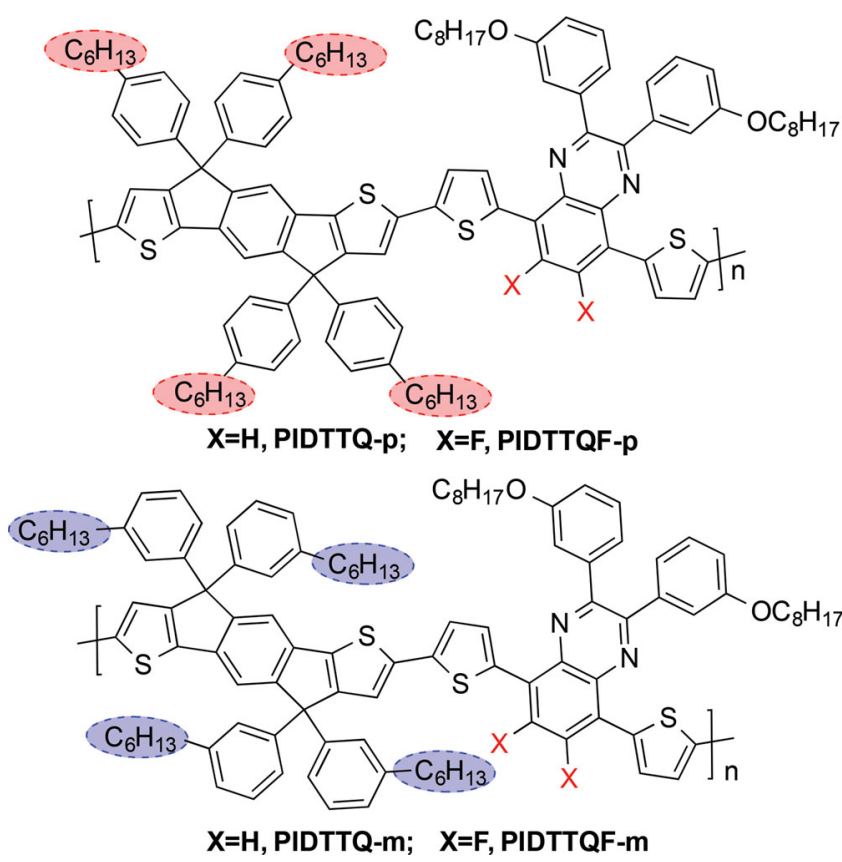

Figure 1. Chemical structures of PIDTTQ-p, PIDTTQ-m, PIDTTQF-p and PIDTTQF-m. 
Table 1. Number-average molecular weight $\left(M_{n}\right)$ and polydispersity index (PDI) measured with size exclusion chromatography (SEC) relative to polystyrene standards.

\begin{tabular}{lcc}
\hline Polymer & $\begin{array}{c}M_{\mathrm{n}} \\
{\left[\mathrm{kg} \mathrm{mol}^{-1}\right]}\end{array}$ & PDI \\
\hline PIDTTQ-p & 29 & 2.1 \\
PIDTTQ-m & 51 & 2.4 \\
PIDTTQF-p & 32 & 2.3 \\
PIDTTQF-m & 46 & 2.3 \\
\hline
\end{tabular}

the highest molecular weights, which were still soluble in chloroform, chlorobenzene, and o-dichlorobenzene (oDCB). The number-average molecular weights $\left(M_{\mathrm{n}}\right)$ of the meta-substituted polymers, PIDTTQ-m and PIDTTQF-m, were noticeably higher than those of the para-substituted polymers, PIDTTQ-p and PIDTTQF-p (Table 1), which agrees well with our previous study. ${ }^{[9 a]}$

In order to investigate if the polymers form aggregates in solution or the solid state, we recorded a series of UV-vis absorbance spectra (Figure 2), which are comparable for all four copolymers when dissolved in chloroform solution. We observed only a slight red-shift upon solidification, which suggests that the copolymers investigated here have either already aggregated in solution or remain largely disordered in the solid state. ${ }^{[7]}$ We performed grazing-incidence wide-angle X-ray scattering (GIWAXS) on thin films to study the solid state order in more detail (Supporting Information, Figure S1). The diffraction patterns of all four copolymers are dominated by a broad halo, which indicates a large degree of disorder. The peak intensity of this amorphous halo is higher in the out-of-plane direction and corresponds to a spacing of about $d_{\text {halo }}=2 \pi / q_{\text {halo }} \approx$ $4 \AA$ (Table 2 ), which likely reflects the average $\pi$-stacking distance between adjacent polymer backbones. We note that for the non-fluorinated as well as the fluorinated pair of copolymers, meta-substituted polymer chains lie slightly closer to each other. In addition, Scherrer analysis of the amorphous halos of PIDTTQ-m and PIDTTQF-m reveals coherence lengths of 14 and $12 \AA$, respectively, (Table 2), which suggests that coherent domains only span about four polymer backbones. For PIDTTQ-p and PIDTTQF-p the coherence lengths are even shorter, with 9 and $10 \AA$, respectively. Thus, we propose that all the copolymers remain largely disordered in the solid state, which is consistent with previously reported IDT polymers. . $^{\text {[a] }}$

With the aim to better understand the likely molecular conformation of the IDT copolymers we performed a series of density functional theory (DFT) calculations using a GGA functional PW91 ${ }^{[11]}$ with a double numerical plus d-functions on heavy elements and p-functions on hydrogen, DNP (basis file 4.4). Trimers with full side chains were taken as a model system. We find that the trimer backbones are fairly planar but slightly curved (Supporting Information, Figure S2). The conjugated backbone of either trimer is surrounded by a dense side-chain lining, which is likely to prohibit backbone stacking and thus explains why the corresponding polymers are amorphous. We note that the meta-substituted side chains of the PIDTTQ-m trimer wrap tightly around the planar backbone (Figure 2). In contrast, for the PIDTTQ-p trimer we observe that para-substituted side chains
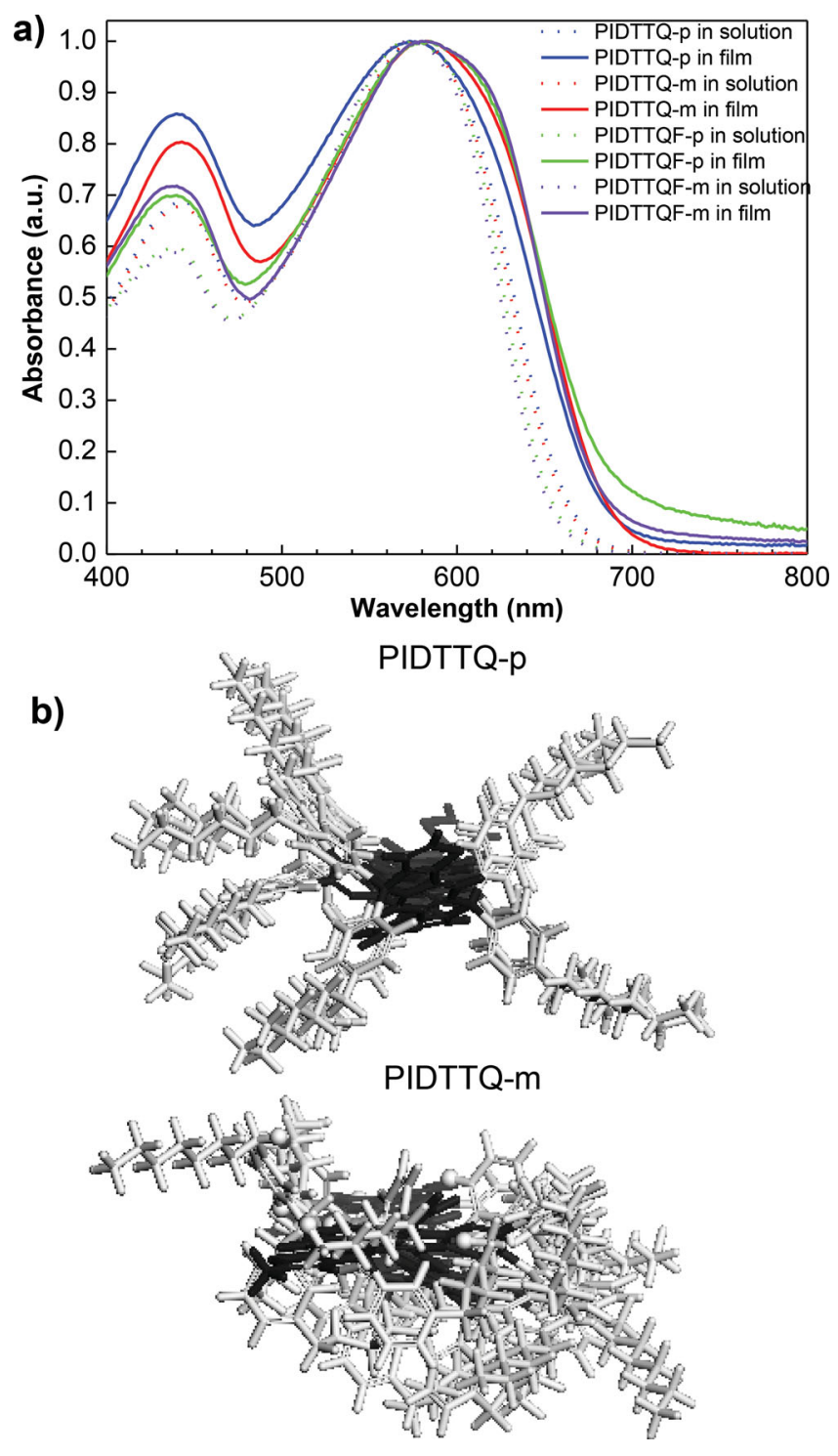

Figure 2. a) Normalized UV-vis absorption spectra of the four IDT copolymers in chloroform solution $\left(1 \times 10^{-5} \mathrm{~mol} \mathrm{~L}^{-1}\right)$ and in the solid state. b) Stick-models of PIDTTQ-p and PIDTTQ-m trimers that were constructed based on DFT calculations with projection along the conjugated backbone (backbone black, side chains gray).

extend further from the conjugated backbone in all directions. We propose that this extended side-chain conformation in the case of the para-substituted copolymers gives rise to increased

Table 2. Peak $d_{\text {halo }}$ and Scherrer coherence length of amorphous halo, optical bandgap $E_{\mathrm{g}, \mathrm{opt}}$, and HOMO and LUMO energy levels.

\begin{tabular}{lccccc}
\hline Polymer & $\begin{array}{c}d_{\text {halo }} \\
{[\AA]}\end{array}$ & $\begin{array}{c}\text { Coherence length } \\
{[\AA]}\end{array}$ & $\begin{array}{c}E_{\mathrm{g}, \mathrm{opt}} \\
{[\mathrm{eV}]}\end{array}$ & $\begin{array}{c}\mathrm{HOMO} \\
{[\mathrm{eV}]}\end{array}$ & $\begin{array}{c}\text { LUMO } \\
{[\mathrm{eV}]}\end{array}$ \\
\hline PIDTTQ-p & $4.23 \pm 0.03$ & $9.0 \pm 1.0$ & 1.78 & -5.65 & -3.65 \\
PIDTTQ-m & $4.09 \pm 0.03$ & $13.5 \pm 0.6$ & 1.79 & -5.68 & -3.66 \\
PIDTTQF-p & $4.10 \pm 0.03$ & $9.6 \pm 0.8$ & 1.74 & -5.75 & -3.61 \\
PIDTTQF-m & $4.03 \pm 0.03$ & $12.4 \pm 0.8$ & 1.76 & -5.78 & -3.63 \\
\hline
\end{tabular}


Table 3. Photovoltaic parameters of optimized solar cells (average PCE of 20 optimized devices in brackets) and hole mobility $\mu_{\text {hole }}$ from field-effect transistors (FETs).

\begin{tabular}{|c|c|c|c|c|c|c|c|}
\hline Polymer & Polymer:PC ${ }_{71} B M$ & $\begin{array}{c}T_{\text {anneal }} \\
{\left[{ }^{\circ} \mathrm{C}\right]}\end{array}$ & $\begin{array}{c}\int_{\mathrm{sc}} \\
{\left[\mathrm{mA} \mathrm{cm}^{-2}\right]}\end{array}$ & $\mathrm{FF}$ & $\begin{array}{l}V_{o c} \\
{[V]}\end{array}$ & $\begin{array}{l}\text { PCE } \\
{[\%]}\end{array}$ & $\begin{array}{c}\mu_{\text {hole }} \\
{\left[\mathrm{cm}^{2} \mathrm{~V}^{-1} \mathrm{~s}^{-1}\right]}\end{array}$ \\
\hline PIDTTQ-p & $1: 3.5$ & 180 & 12.3 & 0.70 & 0.85 & $7.3(7.1)$ & $0.006 \pm 0.002$ \\
\hline PIDTTQ-m & $1: 3.5$ & 160 & 12.9 & 0.69 & 0.88 & $7.8(7.5)$ & $0.013 \pm 0.001$ \\
\hline PIDTTQF-p & $1: 2$ & 130 & 10.4 & 0.59 & 0.92 & $5.7(5.4)$ & $0.010 \pm 0.001$ \\
\hline PIDTTQF-m & $1: 2$ & 130 & 11.7 & 0.59 & 0.96 & $6.6(6.4)$ & $0.021 \pm 0.001$ \\
\hline
\end{tabular}

steric hindrance between adjacent chains and, hence, a larger distance between polymer backbones (cf. discussion on GIWAXS patterns).

To investigate the HOMO and LUMO energy levels of the polymers, square wave voltammetry (SWV) was carried out (Table 2 and Supporting Information Figure S3). PIDTTQ-m and PIDTTQF-m feature $30 \mathrm{mV}$ deeper HOMO levels compared to their corresponding para-substituted counterparts, which can be attributed to the stronger electron donating effect of the alkyl group on the para-position of the pendant phenyl ring. ${ }^{[12]}$ Furthermore, the two fluorinated copolymers display reduced HOMO levels compared to the non-fluorinated materials due to the electron-withdrawing effect of the fluorine atoms. ${ }^{[10]}$

We investigated the photovoltaic performance of the four copolymers in $\mathrm{BHJ}$ solar cells with the conventional device architecture of ITO/PEDOT:PSS/active layer/Ca/Al and an active area of $10 \mathrm{~mm}^{2}$ under AM 1.5G simulated solar light $\left(100 \mathrm{~mW} \mathrm{~cm}{ }^{-2}\right)$. Phenyl- $\mathrm{C}_{71}$-butyric acid methyl ester $\left(\mathrm{PC}_{71} \mathrm{BM}\right)$ was used as the acceptor because of its good light absorption across the visible spectrum. ${ }^{[13]}$ The device efficiency was optimized with respect to i) the processing solvent (oDCB), ii) the active layer thickness, iii) the copolymer: $\mathrm{PC}_{71} \mathrm{BM}$ ratio, and iv) post-deposition annealing conditions of the active layer before cathode deposition (see Table 3 for parameters of optimized solar cells and Figure 3 for current density-voltage characteristics). The reliability of the performed device characterization was ensured by preparation of 20 optimized devices for each copolymer: $\mathrm{PC}_{71} \mathrm{BM}$ blend. Optimized solar cells based on meta-substituted copolymers display a superior open-circuit voltage $\left(V_{\mathrm{oc}}\right)$ and short-circuit current density $\left(U_{\mathrm{sc}}\right)$ compared to para-substituted copolymers, which results in a higher PCE. We note that the PCE of optimized PIDTTQ-p: $\mathrm{PC}_{71} \mathrm{BM}$ solar cells is $7.3 \%$, which is comparable to the results obtained by Guo et al. for the same blend but a smaller active area of only $4 \mathrm{~mm}^{2}(7.5 \%){ }^{[8]}$ Encouragingly, the use of the meta-substituted copolymer PIDTTQ-m results in a clear improvement in PCE to $7.8 \%$.

As anticipated, the $V_{\text {oc }}$ of optimized solar cells scales with the energy of the copolymer HOMO levels with high values that range from $0.85 \mathrm{~V}$ for PIDTTQ-p:PC ${ }_{71} \mathrm{BM}$ to $0.96 \mathrm{~V}$ for PIDTTQF-m:PC ${ }_{71} B M$. It was noted that the meta-substituted copolymers exhibit a higher $V_{\text {oc }}$ compared to the corresponding para-substituted analogues. We rationalize this behavior with the deeper HOMO levels of the meta-substituted copolymers. In addition, this is also consistent with the phenomenon disclosed in our previous work, where polymers with meta-substituted side chains exhibited higher $V_{\text {oc }}{ }^{\left[{ }^{[a]}\right]}$ Devices based on the two fluorinated copolymers feature a slightly higher $V_{\text {oc }}$, which agrees with previous reports. ${ }^{[10]}$ It is worth noting that PIDTTQF-m:PC ${ }_{71} \mathrm{BM}$ solar cells exhibited a remarkably high $V_{\mathrm{oc}} \approx 0.96 \mathrm{~V}$ together with a high $\mathrm{PCE} \approx 6.6 \%$, which hence represents one of few high-performance systems that can provide such a high photovoltage. ${ }^{[14]}$ This good photovoltaic performance, combined with the narrow absorption spectrum of PIDTTQF-m:PC ${ }_{71} \mathrm{BM}$ blends, shows great potential for use in tandem solar cells. ${ }^{[15]}$

In order to better understand the photocurrents of optimized solar cells we performed a series of external quantum efficiency (EQE), GIWAXS, atomic force microscopy (AFM) and field-effect transistor (FET) measurements. For all opti-
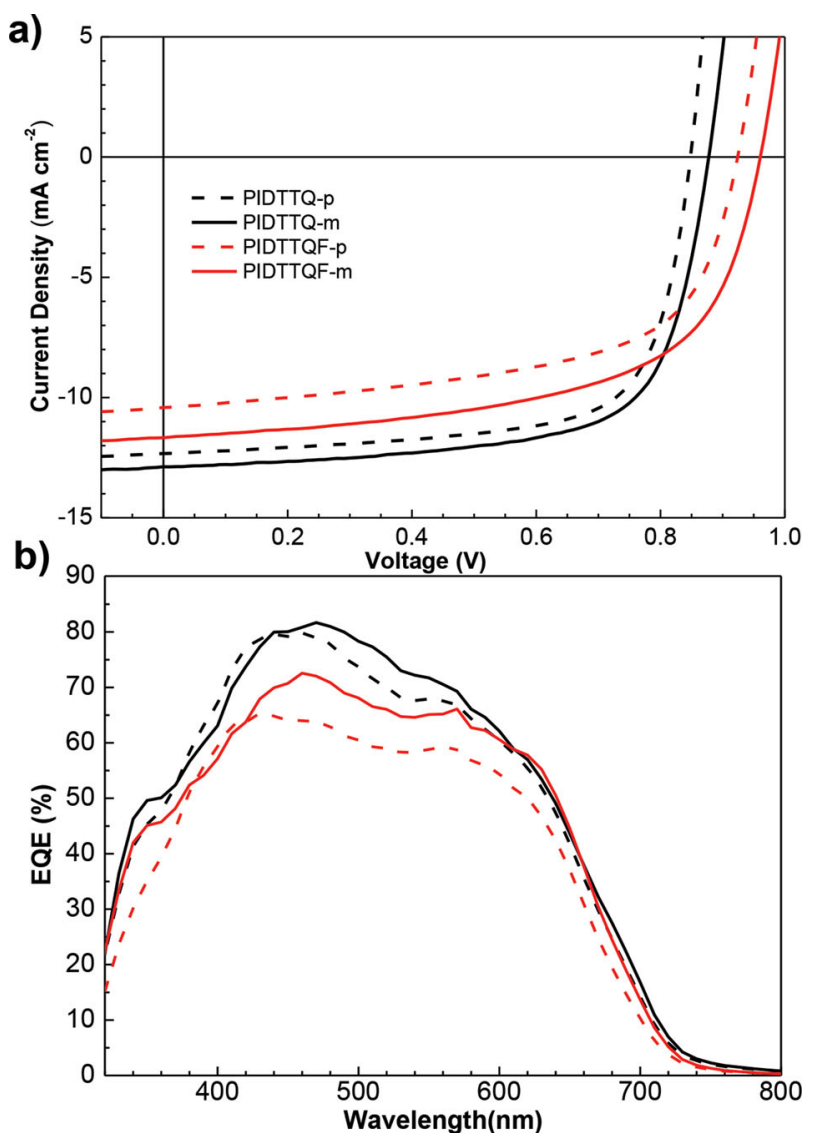

Figure 3. a) Current density-voltage characteristics of IDT copolymer: $\mathrm{PC}_{71} \mathrm{BM}$ solar cells. b) Corresponding external quantum efficiency (EQE) spectra measured under illumination with monochromatic light. 

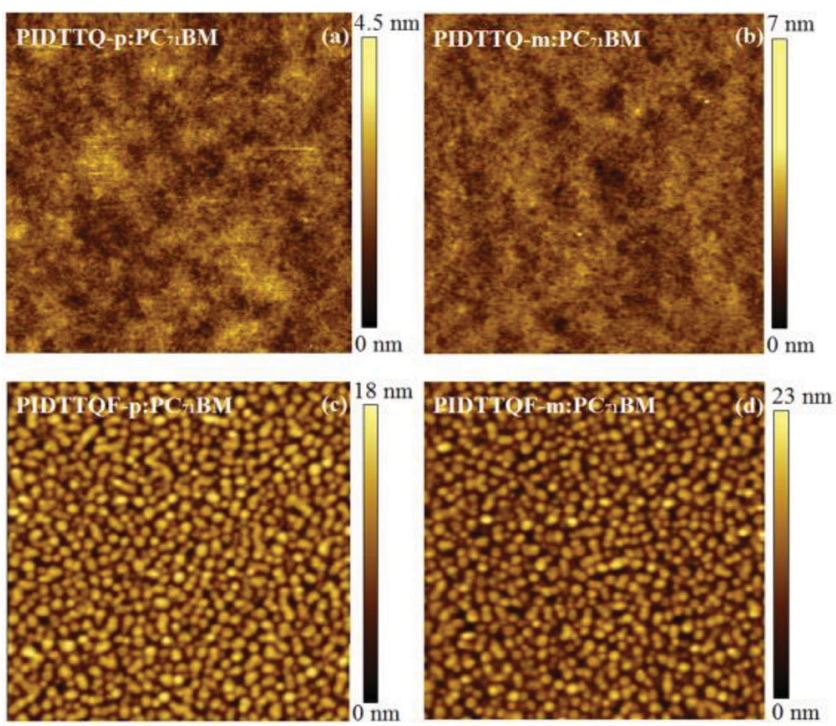

Figure 4. AFM topography images of optimized IDT copolymer:PC $C_{71} B M$ active layers. Size of images $4 \mu \mathrm{m} \times 4 \mu \mathrm{m}$.

mized devices, the photocurrent obtained by integration of the corresponding EQE spectra agrees well with the $J_{\mathrm{sc}}$ obtained from current density-voltage measurements (Figure 3). GIWAXS patterns of all four blends indicate the absence of ordered polymer and fullerene domains (Supporting Information, Figure S1). A broad amorphous halo typical for $\mathrm{PC}_{71} \mathrm{BM}$ is observed in all four blends, which indicates the presence of relatively pure domains of the acceptor material. AFM images of fluorinated copolymer: $\mathrm{PC}_{71} \mathrm{BM}$ blends reveal 100-200 nm large domains and a rough surface with a root mean square (RMS) roughness of $3.1 \mathrm{~nm}$ for PIDTTQF-p: $\mathrm{PC}_{71} \mathrm{BM}$ and $3.7 \mathrm{~nm}$ for PIDTTQF-m:PC $\mathrm{P}_{71} \mathrm{BM}$ (Figure 4). We propose that poor miscibility of the two blend components leads to a nonoptimal nanostructure, which limits the photocurrent of corresponding devices. In contrast, AFM images of non-fluorinated copolymer: $\mathrm{PC}_{71} \mathrm{BM}$ blends have a well-mixed appearance with a RMS roughness below $0.5 \mathrm{~nm}$ for both PIDTTQ-m:PC ${ }_{71} \mathrm{BM}$ and PIDTTQ-p:PC $\mathrm{C}_{71} \mathrm{BM}$, which correlates with the similar $J_{\mathrm{sc}}$ obtained for the corresponding solar cells. Finally, we would like to point out that the hole mobilities of the copolymers as measured in bottom contact, bottom gate field-effect transistors (FETs) are all on the order of $10^{-2} \mathrm{~cm}^{2} \mathrm{~V}^{-1} \mathrm{~s}^{-1}$ (Table 3), which corroborates that the observed variations in photocurrent are due to differences in the nanostructure of the investigated $\mathrm{BHJ}$ blends.

In conclusion, we have designed and synthesized two pairs of IDT-based copolymers with meta-hexyl-phenyl or para-hexylphenyl side chains on the IDT unit. In the case of both fluorinated and non-fluorinated copolymers, the meta-substituted copolymers offer better solubility, higher molecular weight and a superior photovoltaic performance. Solar cells based on BHJ blends of the fluorinated IDT copolymer PIDTTQF-m and $\mathrm{PC}_{71} \mathrm{BM}$ offer a high $V_{\text {oc }}$ of $0.96 \mathrm{~V}$ and a PCE of up to $6.6 \%$, which makes this material interesting for tandem devices. Nonfluorinated PIDTTQ-m:PC $\mathrm{P}_{71} \mathrm{BM}$ devices yield a slightly lower photovoltage but an improved photocurrent due to a more finegrained nanostructure of the active layer blend with a PCE as high as $7.8 \%$, which is the highest solar cell efficiency achieved with IDT-based polymers and represents one of the highest values for donor polymers with band gaps over $1.75 \mathrm{eV}$. The side-chain design strategy disclosed in this work is anticipated to be highly valuable for the molecular design of conjugated polymers for organic electronics.

\section{Experimental Section}

Solar Cell Device Fabrication and Characterization: The structure of the solar cells was glass/ITO/PEDOT:PSS/active layer/Ca/Al. As a buffer layer, the conductive polymer, PEDOT:PSS (Baytron P VP Al 4083), was spin-coated onto ITO-coated glass substrates, followed by annealing at $160^{\circ} \mathrm{C}$ for $30 \mathrm{~min}$ to remove water. The thickness of the PEDOT:PSS layer was about $40 \mathrm{~nm}$, as determined by a Dektak $6 \mathrm{M}$ surface profilometer. The active layer consisting of polymers and $\mathrm{PC}_{71} \mathrm{BM}$ was spin-coated from o-dichlorobenzene (oDCB) solution onto the PEDOT:PSS layer. The spin-coating was done in a glove box and the films were thermally annealed for $10 \mathrm{~min}$ before they were directly transferred to a vapor deposition system mounted inside of the glove box. $\mathrm{Ca}(10 \mathrm{~nm})$ and $\mathrm{Al}(100 \mathrm{~nm})$ were used as top electrodes and were deposited via a mask in vacuum onto the active layer. The accurate area of every device $\left(10 \mathrm{~mm}^{2}\right)$, defined by the overlap of the ITO and metal electrode, was measured carefully using optical microscopy. PCE was calculated from $J-V$ characteristics recorded by a Keithley 2400 source meter under illumination of an AM1.5G solar simulator with an intensity of $100 \mathrm{~mW} \mathrm{~cm}{ }^{-2}$ (Model SS-50A, Photo Emission Tech., Inc.). The light intensity was determined by a standard silicon photodiode. EQEs were measured using a Newport 2931-C coupled with 300 W Xenon lamp.

Fabrication and Characterization of Field-Effect Transistors: The hole mobilities of the polymers were measured using FETs with a bottomgate, bottom-contact structure. Silicon substrates with a $200 \mathrm{~nm}$ layer of thermally grown oxide and thermally evaporated gold source and drain contacts were treated with an octadecyltrichlorosilane (OTS) selfassembled monolayer. Isotropic films were spun cast from chloroform solution $\left(10 \mathrm{mg} \mathrm{mL}^{-1}\right)$ at $1500 \mathrm{rpm}$. The mobility was evaluated in the linear regime for 3-4 devices per polymer.

\section{Supporting Information}

Supporting Information is available from the Wiley Online Library or from the author.

\section{Acknowledgements}

The authors acknowledge funding from the Swedish Research Council, the Swedish Energy Agency and Chalmers' Areas of Advance Energy, Materials Science and Nanoscience and Nanotechnology for funding as well as National Natural Science Foundation of China (21274161 and 51173199). S.H. would like to thank the National Science Foundation for support in the form of a graduate research fellowship. D.D. and W.C. contributed equally to this work. Use of the Stanford Synchrotron Radiation Lightsource, SLAC National Accelerator Laboratory, is supported by the U.S. Department of Energy, Office of Science, Office of Basic Energy Sciences under Contract No. DE-AC02-76SF00515.

Received: April 22, 2014 Published online: 
[1] a) Y. F. Li, Acc. Chem. Res. 2012, 45, 723; b) Y. J. Cheng, S. H. Yang, C. S. Hsu, Chem. Rev. 2009, 109, 5868; c) B. C. Thompson, J. M. J. Fréchet, Angew. Chem. Int. Ed. 2008, 47, 58.

[2] G. Yu, J. Gao, J. C. Hummelen, F. Wudl, A. J. Heeger, Science 1995, 270, 1789.

[3] Z. C. He, C. M. Zhong, S. J. Su, M. Xu, H. B. Wu, Y. Cao, Nat. Photonics 2012, 6, 591.

[4] M. C. Scharber, D. Wuhlbacher, M. Koppe, P. Denk, C. Waldauf, A. J. Heeger, C. J. Brabec, Adv. Mater. 2006, 18, 789.

[5] a) N. Blouin, A. Michaud, D. Gendron, S. Wakim, E. Blair, R. Neagu-Plesu, M. Belletete, G. Durocher, Y. Tao, M. Leclerc, J. Am. Chem. Soc. 2008, 130, 732; b) Z. Ma, D. Dang, Z. Tang, D. Gedefaw, J. Bergqvist, W. Zhu, W. Mammo, M. R. Andersson, O. Inganäs, F. Zhang, E. Wang, Adv. Energy Mater. 2014, 4, 1301455; c) Z. Ma, W. Sun, S. Himmelberger, K. Vandewal, Z. Tang, J. Bergqvist, A. Salleo, J. W. Andreasen, O. Inganäs, M. R. Andersson, C. Müller, F. Zhang, E. Wang, Energy Environ. Sci. 2014, 7, 361; d) E. Wang, Z. Ma, Z. Zhang, K. Vandewal, P. Henriksson, O. Inganäs, F. Zhang, M. R. Andersson, J. Am. Chem. Soc. 2011, 133, 14244; e) E. Wang, L. Wang, L. F. Lan, C. Luo, W. L. Zhuang, J. B. Peng, Y. Cao, Appl. Phys. Lett. 2008, 92, 033307.

[6] a) Y. Liang, D. Feng, Y. Wu, S.-T. Tsai, G. Li, C. Ray, L. Yu, J. Am. Chem. Soc. 2009, 131, 7792; b) C. Piliego, T. W. Holcombe, J. D. Douglas, C. H. Woo, P. M. Beaujuge, J. M. J. Fréchet, J. Am. Chem. Soc. 2010, 132, 7595; c) E. Wang, L. T. Hou, Z. Q. Wang, Z. F. Ma, S. Hellstrom, W. L. Zhuang, F. L. Zhang, O. Inganas, M. R. Andersson, Macromolecules 2011, 44, 2067.

[7] a) I. Mcculloch, R. S. Ashraf, L. Biniek, H. Bronstein, C. Combe, J. E. Donaghey, D. I. James, C. B. Nielsen, B. C. Schroeder, W. M. Zhang, Acc. Chem. Res. 2012, 45, 714; b) Y.-C. Chen, C.-Y. Yu, Y.-L. Fan, L.-I. Hung, C.-P. Chen, C. Ting, Chem. Commun. 2010, 46,
6503; c) Y. Zhang, J. Zou, H.-L. Yip, K.-S. Chen, D. F. Zeigler, Y. Sun, A. K. Y. Jen, Chem. Mater. 2011, 23, 2289.

[8] X. Guo, M. J. Zhang, J. H. Tan, S. Q. Zhang, L. J. Huo, W. P. Hu, Y. F. Li, J. H. Hou, Adv. Mater. 2012, 24, 6536.

[9] a) E. Wang, J. Bergqvist, K. Vandewal, Z. Ma, L. Hou, A. Lundin, S. Himmelberger, A. Salleo, C. Müller, O. Inganäs, F. Zhang, M. R. Andersson, Adv. Energy Mater. 2013, 3, 806; b) L. T. Hou, E. Wang, J. Bergqvist, B. V. Andersson, Z. Q. Wang, C. Muller M. Campoy-Quiles, M. R. Andersson, F. L. Zhang, O. Inganas, Adv. Funct. Mater. 2011, 21, 3169; c) E. Wang, L. T. Hou, Z. Q. Wang, S. Hellström, F. L. Zhang, O. Inganäs, M. R. Andersson, Adv. Mater. 2010, 22, 5240 .

[10] a) D. Dang, W. Chen, R. Yang, W. Zhu, W. Mammo, E. Wang, Chem. Commun. 2013, 49, 9335; b) S. Albrecht, S. Janietz, W. Schindler J. Frisch, J. Kurpiers, J. Kniepert, S. Inal, P. Pingel, K. Fostiropoulos, N. Koch, D. Neher, J. Am. Chem. Soc. 2012, 134, 14932.

[11] J. P. Perdew, Y. Wang, Phys. Rev. B. 1992, 45, 13244

[12] Y. Huang, M. Q. Zhang, L. Ye, X. Guo, C. C. Han, Y. F. Li, J. H. Hou, J. Mater. Chem. 2012, 22, 5700.

[13] M. M. Wienk, J. M. Kroon, W. J. H. Verhees, J. Knol, J. C. Hummelen, P. A. van Hal, R. A. J. Janssen, Angew. Chem. Int. Ed. 2003, 42, 3371

[14] a) K. Wang, Y. Zhao, W. Tang, Z.-G. Zhang, Q. Fu, Y. Li, Org. Electron. 2014, 15, 818; b) J. Yuan, Z. Zhai, H. Dong, J. Li, Z. Jiang Y. Li, W. Ma, Adv. Funct. Mater. 2013, 23, 885; c) J. Jo, A. Pron, P. Berrouard, W. L. Leong, J. D. Yuen, J. S. Moon, M. Leclerc, A. J. Heeger, Adv. Energy Mater. 2012, 2, 1397.

[15] a) J. You, L. Dou, K. Yoshimura, T. Kato, K. Ohya, T. Moriarty, K. Emery, C. C. Chen, J. Gao, G. Li, Y. Yang, Nat. Commun. 2013 4, 1446; b) W. W. Li, A. Furlan, K. H. Hendriks, M. M. Wienk, R. A. J. Janssen, J. Am. Chem. Soc. 2013, 135, 5529. 